By WILLIAM S. BUDINGTON

\title{
Teaching the Use of Engineering Libraries
}

Mr. Budington is librarian, Engineering and Physical Sciences, Columbia University.

$\triangle$ MONG THE many problems faced by 1 librarians today is the business of salesmanship. Most of us are familiar with the usual devices some of which we employ, others of which we enviously watch in use elsewhere-such as displays, lists, advertisements and radio broadcasts. At colleges and universities we have a head start in that education depends heavily on library resources. There is still a definite selling job to do-selling the faculty and especially the students the concept of the library as a working tool rather than a stockroom.

Salesmanship is largely a matter of personal contact, no less in libraries than in business. Our most effective work lies in direct dealing with the public through formal or informal guidance or instruction. Teaching the use of libraries formally is carried out in several ways: the freshman orientation tour, a short talk by the librarian in a program meeting, the inclusion of one or more library periods in a subject course and the separate library course. The latter is becoming more and more common, and interest in it is increasing. In engineering schools, however, little at this level has yet appeared. Since the course given at Columbia University appears to be one of the first, it may be appropriate to describe

\footnotetext{
1 Presented at meeting of Engineering School Libraries Section, A.C.R.L., Cleveland, July 18, I950.
}

it briefly before passing on to general discussion.

At present, Engineering 3 is a one-point, one-hour-a-week course required of all undergraduate engineering students. Titled "Engineering Library Technique" it is taught by the engineering librarian and is given during both winter and spring semesters. Each of the seven engineering curricula (mechanical, electrical, industrial, etc.) has a section to itself and, as far as possible, students are registered for the appropriate section. These usually have from 15 to 40 students, depending on the subject, and sometimes two sections are necessary for heavily enroled curricula.

Such instruction was initiated in 1933 in the form of library periods in one of the regular subject courses. This was expanded to a series of three lectures required of all students, then to a full semester, noncredit, required course. Since 1945 one point of credit has been given.

The present content of the course largely follows traditional lines. The approach is by form of material. The beginning is made with principles of classification, the card catalog and the making of proper references. Guides to the literature, encyclopedias and handbooks, national bibliographies, review sources and other bibliographies of various types then follow. The importance and use of serial literature brings in general and special technical indexing and abstracting. Standards and government documents, trade literature and 
directories have their part, and we conclude with something on documentary production and reproduction, microfilm and the like. In all, I 5 lecture periods are planned. The example are chosen to fit the major subject of each section. Many items are given to all sections, but wherever possible the class periods are tailored to fit.

Each student, as his project for the course, completes a bibliography on a topic of his choosing subject to the instructor's approval. The number of references and the number of sources from which they are obtained are specified. This precludes comprehensive bibliographies, but our intent is to obtain a fairly comprehensive coverage of sources rather than intensive searching. Although exceptions are made for thesis projects, we hope that students will thus come to recognize the value of source material in related fields as well as in their own. As a rule there have been no tests, daily assignments or final examinations. With two or three hundred students there is a limit to our capacity for including them. Attendance is regulated by general university procedure.

This course is taken during the junior year by all except chemical engineers who take it as seniors. It comes during their first year in the School of Engineering since the lower two years are spent in Columbia College or the School of General Studies. Thus our students have had college experience, and one-half to two-thirds of them have received some library orientation in high school or college.

There is no need to elaborate greatly on the reason for some such instruction. Occupied with the technics of laboratory and classroom, the student engineer often does not realize that the library offers as much in value as the rest of his curricula. In the humanities, one's contact with library resources is more extended and more en- forced. It must be brought home to students of science and engineering that familiarity with current progress is an absolute necessity. There is a need for recognition of what has gone before, and a realization that knowledge has been recorded for many centuries before the student became a novitiate engineer. $\mathrm{He}$ should become familiar with the major library tools of research, and with the extent of the literature in his own field. It is well that he learn that English is by no means the sole language of communication. If he is to be aware of the world's work, he must acquire a working knowledge of foreign tongues.

Basically, the library must be dissected and the machinery of its use made clear. The student should come to understand bibliographic practice as it affects his library research and the preparation of reports and articles. When Columbia's course originated, the dean's announcement said, "The engineering libraries are for the use and convenience of the students. The school is anxious that every student should learn the possibilities of an engineering library." This has been extended to include the meaning and significance of engineering literature and its organization.

In a number of schools, such instruction is given on a graduate level, for credit in many instances and even required in a few. The advantage to the graduate student is unquestioned. That undergraduates as well may benefit is not as often recognized. There is no reason why they, too, should not have the ability to dig out information for themselves. A noticeable improvement in report work for other courses was one of the reasons the Columbia lectures were expanded. Such an undergraduate course deals with more elementary materials than a graduate offering and may be less intensive since immediate original research is 
not contemplated. There is a very definite problem in getting across to undergraduates the need for such information, whereas a graduate student facing a thesis is acutely aware, or shortly will be, of the complexities of technical literature and his own shortcomings.

Choice of the instructor is up to the school, of course. From the professional point of view, this duty is rightfully the librarian's and so it is usually found. Teaching ability is an important factor which is likely to be minimized in the decision, "Let the librarian do it." It is particularly important in the undergraduate course, as mentioned before. Knowledge of the literature is another obvious prerequisite; faculty members and specialists know better than the librarian the literature of their own subjects, but for coverage of all fields a bevy of such men would be required. A competent librarian will have general acquaintance and familiarity with the materials of all branches of engineering. In addition, a more uniform scheme is assured if instruction is centralized, and related fields may be tied in more easily.

Another point gained by the librarian's instructorship relates to the library's position in the educational pattern. As a fellow teacher, the librarian is more likely to be considered a colleague by the faculty, as eloquently argued by B. Lamar Johnson in his book The Librarian and the Teacher in General Education. Furthermore, he is brought in contact with most, if not all students, early in their engineering studies. There is established an acquaintanceship which makes easier the students' later use of the library and engenders a working basis for further guidance.

As in nonscience curricula, library instruction may be correlated with subject courses. Frequently, students are required to present a senior thesis. Through con- sultation with the department, it is possible to adjust requirements and emphases toward that specific end. Where departmental research is under way, students in the library course are able to do some of the bibliographical groundwork, thus aiding the department as well as themselves.

The question of the proper time for giving such a course may be open to comment. The junior year appears to have several advantages to recommend it. At this point the student is entering his major field of work and may be assumed to have a definite subject interest, giving point and direction to any library work done. An added maturity over first-year students also makes the task of teaching easier. This is not to say that a first-year introduction to the library is undesirable; the freshman orientation tour or practice work in the English course familiarizes the student with the library's principal features-notably its location and arrangement. Extensive instruction, however, should wait until the teaching can be done in terms of the subject field rather than in terms of pure bibliography.

Credit for such a course should be arranged if at all possible. Its length, the time spent on it and its required status are all deserving of recognition, not to speak of its real contribution to the training of engineers. A noncredit course stands much less chance of attention from the students and consideration from the faculty.

The content of the course will be largely a matter of individual organization, much as with any other subject course. The various elements described in the Columbia course are fairly standard items for inclusion, and others can be developed depending on circumstances. The number of students, the types of curricula, size of library and staff, and physical facilities will affect the content and teaching methods. Library 
tours or instruction periods in the library may be handled if conditions permit. Guest lecturers from the faculty help to vary the program and lend a certain meaning and authority. With large classes a lecture schedule is usually called for, with less in the way of tests, homework and the like. Small classes permit the use of problems and more individual attention. Teaching aids may include pictures, enlargements, charts and samples. Slides have been used in some similar courses, although we have not yet attempted them in our large classes. Copies of books and materials are brought to class for use with the lecture and are there after class for examination. During the semester these materials are kept on a separate shelf in the reading room for the students' use.

Whatever teaching methods are used, great emphasis must be placed on practical uses. Examples should contain the technical vocabulary, and all explanations be made in those terms. The instructor must have a fair understanding of engineering subjects in order to explore the nuances of subject headings. In brief, the work must be strictly from the engineering point of view, and made, as far as possible, an engineering course in the literature rather than a library course for engineers.

The results from the course are rather difficult to pin down. The work turned in indicates how well students have grasped the principles of library research, but the application elsewhere of what has been learned is often not known. Our best indications come when we occasionally see their reports, and especially when we note the activity at the catalog, the indexes, use of bibliographies and the like. Student reaction to a one-point course is not likely to be rapturous, especially when there is not the obvious practicality of some of their other work. In a curricular survey con- ducted by our students, the library course received an over-all average rating slightly above the humanities and slightly below many of the engineering subjects. Our present school administration has been highly in favor of it, and it would be difficult to maintain the course without that support. As a whole, the faculty think it a good idea, though many of them are unclear as to just what it is all about. As might be expected, those faculty members who make considerable use of the library are more sympathetic than those who rarely pass through our portals.

Perhaps our most pleasant recommendations come from graduates who drop back for a visit. Frequently they tell of research work or assignments in which knowledge of information sources was an advantage. Sometimes undergraduates or graduates will call in knowing that there is a volume which will answer their questions, though perhaps not remembering its name. Even this is certainly better than floundering about in aimless search or prematurely assuming the unavailability of the desired material.

Similar coverage appears in science-technology literature courses found in library schools. More emphasis is being given to such instruction, and engineering librarians are naturally interested in it, both for their personal benefit and in the hope of trained assistants. Illinois has offered "Bibliography of Science and Technology" since I948, aimed at large public library service and including four periods out of 48 on engineering. At Columbia, the classes in "Science Literature" cover only the basic sciences; medicine has been covered in "Literature of Special Fields," but as yet there has not been sufficient demand in the applied sciences. It would certainly be to our advantage to stimulate such a demand through our own studies and recruiting 
activities. However, I believe there are obvious differences between such library school courses and those given to undergraduate subject students. Their purposes are essentially the same-imparting knowledge of and familiarity with common materials. For the librarian these are the tools of his trade and the instruction must be more complete, more detailed, more comprehensive; for the engineer this knowledge is an adjunct only, and while it would doubtless be nice to include more, the essentials are all he should be expected to acquire. Principles of book selection and trade information are two items which the librarian needs but the engineer does not.

In almost all categories, whether it be bibliographical variations or knowledge of sources, the approach to the subject stems from a different viewpoint. The librarian tends to have greater interest in the book or periodical, per se, as a physical container; its many manifestations, its selection, care and preservation, and accessibility are his concern. The engineer, on the other hand, is interested only in the container's contents; what happens in the long chain of events bringing it to his use is of little or no real interest to him. His background and training have been entirely different. As a rule, he is not overly interested in books but in the accomplishment of factual results and the means for doing so.

Our basic problem is to convince him that the "means for doing so" include the library. Though it differs from what the engineer is accustomed to think of as instrument or apparatus, the written record of scientific knowledge can be fully as important in providing foundations for work and pointing the way. A library course may thus be compared to those in basic mathematics, instrumentation, drafting and other contributory instruction. The more salesmanship we can exercise the better. By familiarizing the engineer with the printed tools of his-and our-trade, we do him and ourselves a service.

\section{Problems Confronting University Libraries}

\section{(Continued from page 240)}

\section{Conclusion}

In conclusion, we trust that the preceding report is of value in its summary of these problems which are apparently of deepest concern and interest to university librarians over a nationwide area. It does describe trends of thought and areas for investigation proposed by a representative group of administrators. In no way is it an attempt to compile a list of all problems confronting university librarians, or to draw conclusions as to which are the most important at this time. This report clearly demonstrates an awareness that established procedures and points of view need periodic re-examination and that new developments require constant observation. Book collections continue to grow phenomenally. Service staffs, correspondingly, must become larger and larger. The American dollar buys less and less. Budgets reflect an inflationary situation. The problems thus posed can be met only through intensive cooperative effort. The University $\mathrm{Li}$ braries Section of A.C.R.L. can and should contribute through the development of an active and expanding program of projects and committee work. 